\title{
ISCHAEMIC DIABETIC MACULOPATHY: A WARNING SIGN IN SOUTH INDIAN POPULATION
}

\section{Arvind Babu', Sindhu Mithun ${ }^{2}$}

${ }^{1}$ Assistant Professor, Department of Ophthalmology, Sri Ramachandra University.

2Post Graduate, Department of Ophthalmology, Sri Ramachandra University.

\section{ABSTRACT}

To study the association between various types of Diabetic Macular Oedema (DME) with systemic risk factors namely hypertension, chronic renal disease and Ischaemic Heart Disease (IHD) in South Indian population.

\section{MATERIAL AND METHODS}

The study was done on 96 eyes of 50 patients. Emphasis was placed on the findings of Fundus Fluorescein Angiography (FFA) to decide about the therapeutic modality.

\section{RESULTS}

32 patients were above 50 years and 18 patients were below 50. Disease affects both eyes, although asymmetrically. In our study, 92\% patients had bilateral involvement. None of the diabetic patients associated with hypertension (6 eyes of 3 patients) had DME. All diabetic patients who had chronic renal disease (100\%) had either diffuse or mixed type of DME; $85 \%$ of patients having history of IHD had ischaemic maculopathy.

\section{CONCLUSION}

Ischaemic maculopathy has no treatment as such, but can definitely be considered as a warning sign for future life-threatening ischaemic cardiac events due to its strong association (85\%) and hence necessary steps of prevention should be taken with help of physicians.

\section{KEYWORDS}

Ischaemic Maculopathy, Fundus Fluorescein Angiography, Ischaemic Heart Disease, Hypertension.

HOW TO CITE THIS ARTICLE: Babu CA, Mithun S. Ischaemic diabetic maculopathy: a warning sign in South Indian population. J. Evolution Med. Dent. Sci. 2016;5(55):3760-3762, DOI: 10.14260/jemds/2016/861

\section{INTRODUCTION}

Diabetes mellitus is a disorder of carbohydrate metabolism characterized primarily by hyperglycaemia and glycosuria with secondary anomalies of metabolism of proteins and fats. ${ }^{1}$ Diabetic retinopathy is a microangiopathy affecting precapillary arterioles and post-capillary venules. ${ }^{2}$ The most common cause of visual impairment in diabetic retinopathy is macular oedema. ${ }^{3}$ This is due to breakdown of blood retinal barrier. The sites of leakage are microaneurysms, intraretinal microvascular abnormalities and dilated retinal capillaries. ${ }^{4}$

\section{RISK FACTORS}

\section{Duration of Diabetes}

The prevalence and severity of Diabetic Retinopathy is related to duration of diabetes. Retinopathy in IDDM does not occur within 5 years after the onset of the disease. In NIDDM, retinopathy is found within 5 years.

Proliferative Diabetic Retinopathy is more common in IDDM. This is due to,

1. Proliferative Diabetic Retinopathy results from higher blood glucose levels for longer period.

2. It results from certain metabolic state of retina, which is present in IDDM.

Financial or Other, Competing Interest: None.

Submission 04-06-2016, Peer Review 29-06-2016,

Acceptance 04-07-2016, Published 09-07-2016.

Corresponding Author:

Dr. C. Arvind Babu,

Sri Ramachandra University,

No. 1 Ramachandra Nagar,

Porur, Chennai-116.

E-mail: arvindmed23@yahoo.com

DOI: $10.14260 /$ jemds $/ 2016 / 861$
Clinically significant macular oedema was not found in younger onset persons with less than 5 years diabetes. In contrast, it is present in older onset persons with first few years of diabetes. When non-proliferative diabetic retinopathy is present, older patients have macular oedema more frequently than younger onset persons.

When proliferative diabetic retinopathy is present, the prevalence of maculopathy is same in IDDM and NIDDM. Macular oedema is a more common NIDDM. When young individuals have macular oedema, it is usually associated with Proliferative Diabetic Retinopathy.

\section{Age}

Diabetic children are less prone to retinopathy. Risk factors during puberty due to hormonal and metabolic changes.

\section{Metabolic Control}

Positive correlation occurs between poor metabolic control and severity of retinopathy. Worsening of retinopathy can occur following rapid control of blood glucose with appearance of cotton wool spots and IRMA. ${ }^{5}$

\section{Clinically Significant Macula Oedema}

- Retinal oedema within 500 microns of the center of the fovea.

- Hard exudates within 500 micron of the fovea, if associated with adjacent retinal thickening.

- Retinal oedema that is one disc area or larger, any part of which is within one disc diameter of the center of fovea. ${ }^{5}$ 


\section{Pathological Changes in Maculopathy}

- Microaneurysms: Microaneurysms are first ophthalmoscopically detectable sign of maculopathy results from progression of capillary disease. It tends to occur first along the temporal raphe predominantly on the cellular side of the capillary bed. The formation of microaneurysms reflects the disappearance of the intramural pericytes. The distribution of the microaneurysms ranges from the patchy geographical distribution in early maculopathy to scattering throughout the posterior retina in advanced maculopathy.

- Exudates: Following the development of the ischaemic foci, deep circumscribed hard yellow exudates developed at the macula. Because the outer plexiform layer at the macula has a large potential interstitial space between cells, the earliest exudative material is located in this region. The exudates distort the normal surrounding cells of the retina. The surrounding cellular elements of the outer plexiform layer undergo secondary degeneration to produce necrotic foci, which give a Swiss cheese appearance to the histological section of the posterior retina.

- Macular oedema: Macular oedema is a distinct process where serous fluid accumulate within the retinal layers. The fluid accumulates first in the microcystic spaces in the retinal layer and then the cystic spaces containing serous fluid. These eventually lead to major decrease in visual acuity. Oedema of fovea due to loss of the perifoveal capillary bed is commonly seen in juvenile onset diabetes. It may also occur following photocoagulation treatment.

- Macular Ischaemia: Assessing the blood supply to macula is important, because inadequate blood supply may itself cause a decrease in visual acuity. Macular ischaemia may be divided into three types.

- Focal capillary dropout.

- Enlargement of the normal FAZ secondary to occlusion of the perifoveal capillaries.

- Non-perfusion of large areas of the macula occurs with occlusion of precapillary arterioles or larger retinal arterioles.

- Preretinal and vitreoretinal changes: It is due to proliferation and shrinkage of fibrous, glial and fibrovascular tissues. 6

\section{Vulnerability of Macula is Due to}

- Abundance of Henle's fibres, which are hydrophilic.

- Relative avascularity, which limits fluid absorption.

- Thin basal lamina which offers little protection against any biochemical effects.

\section{Types of Macula Oedema}

1. Focal macular oedema: Localized area of retinal thickening results from microaneurysms and IRMA. They are delineated from normal retina by complete or partial ring of exudates. Subretinal deposits occurs in severe cases.

2. Diffuse macular Oedema: Occurs from dilated vessels at posterior pole. Patent capillaries dilate and leak to cause diffuse oedema. It is not usually associated with hard exudates. Bilateral symmetry is a common feature.
Systemic fluid retention due to renal disease can increase macular oedema. Disturbance in permeability of either retinal capillaries, endothelium, retinal pigment epithelium results in retinal oedema. It can follow pan-retinal photocoagulation.

3. Ischaemic macular oedema: Ischaemic maculopathy occurs when changes such as enlargement and blockage affect the capillaries. It can only occur when there is some degree of macular oedema. The capillary loss affects the fovea and nearby areas and causes severe visual loss which does not respond to treatment. 3,7

\section{Clinical Evaluation of Macula}

Symptoms include defective vision positive ascotomas, metamorphopsia, micropsia and vertical diplopia due to tractional detachment of macula.

\section{AIM}

To study the association between various types of Diabetic Macular Oedema (DME) with systemic risk factors namely hypertension, chronic renal disease and Ischaemic Heart Disease (IHD) in South Indian population.

\section{MATERIAL AND METHODS}

- The study was done on 96 eyes of 50 patients. Emphasis was placed on the findings of Fundus Fluorescein Angiography (FFA) to decide about the therapeutic modality. Best corrected visual acuity was noted using Snellen chart. Intraocular pressure was measured using Goldmann's applanation tonometry. Evaluation of anterior segment was done using slit lamp. Fundus examination was done using slit lamp biomicroscopy with +78D lens supplemented by indirect ophthalmoscope. Status of angle and vitreous cavity was assessed by Goldmann three mirror gonio lens. Fundus photograph and FFA was done using Zeiss fundus photo camera. Laser photocoagulation was performed by Zeiss double frequency Nd:YAG laser. Blood pressure was measured using sphygmomanometer. Renal function tests, baseline ECG/2D echo was done wherever necessary. Physician/Cardiologist's opinion was taken wherever necessary. Patients with diabetes either referred or detected at Sri Ramachandra Hospital were taken into study. Associated systemic factors like hypertension, renal disease and ischaemic heart disease were recorded. FFA was done using $5 \mathrm{~mL}$ of $10 \%$ sodium fluorescein. The dye is injected intravenously into the antecubital vein with the patient seated in front of the fundus camera. After FFA, patients were classified accordingly.

- Focal DME.

- Diffuse DME.

- Ischaemic DME.

\section{RESULTS}

- 32 patients were above 50 years and 18 patients were below 50 years.

- Disease affects both eyes, although asymmetrically. In our study, 92 percent of patients had bilateral involvement.

- None of the diabetic patients associated with hypertension ( 6 eyes of 3 patients) had DME. 
- All diabetic patients who had chronic renal disease $(100 \%)$ had either diffuse or mixed type of DME.

- $\quad 85 \%$ of patients having history of IHD had ischaemic maculopathy.

\section{ANALYSIS AND DISCUSSION}

\section{Lesions in FFA:}

1. Focal lesions: The hard exudates have microaneurysms at their centre. On angiogram microaneurysms are seen as hyperfluorescent spots. Some may not perfuse or perfuse slowly. They appear as dark silhouettes on angiogram. Leakage of microaneurysms can occur. Hard exudates and haemorrhages produce blocked fluorescein.

2. Diffuse lesions: Angiography shows dilatation of capillaries and leak in the early arteriovenous phase. Cystoid pattern can occur. The dye persists for a long time.

3. Ischaemic Maculopathy: Foveal avascular zone is horizontally oval and measures 300-400. The following changes are seen.

- Enlargement of foveal avascular zone.

- Irregularity of foveal avascular zone.

- Capillary budding into foveal avascular zone.

- Widening of intercapillary spaces and capillary dropouts in the perifoveal area. ${ }^{8}$

\section{Age Incidence}

In our study the predominant age group affected is the 51-60 years range $32 \%$ followed by $61-70$ years range $26 \%$ and 41 50 years range $22 \%$. In our study $54 \%$ cases are aged between 41-60. This correlates with the Wisconsin Epidemiologic Study of Diabetic Retinopathy, which revealed diabetic retinopathy more prevalent in the middle aged and elderly population affecting people aged 45 to 64 years. ${ }^{9}$

\section{Table 1/Sex Incidence}

The ratio of males-to-females in our study is $2.85: 1$. The predominant age group in which males and females were affected was between 51-60 years. The WISCOSIN epidemiological study of diabetic retinopathy (1984) showed male, female ratio was 1.5:1.10

\section{Table 2/Laterality}

In our study, $92 \%$ of the patients had bilateral involvement. This exemplifies the fact that Diabetic Maculopathy affects both eyes, although asymmetrically. ${ }^{11}$

\section{Systemic Ailments}

UKPDS study established that increased blood pressure increases the risk for the development and progression of diabetic retinopathy. Diabetic nephropathy is a risk factor associated with progression of retinopathy and maculopathy. Cardiovascular disease (IHD) accelerates the progression of maculopathy, which is evident in our study, as there is a strong association (85\%) of ischaemic maculopathy.

\begin{tabular}{|c|c|}
\hline Age & Range in Percentage \\
\hline $21-30$ yrs. & $6 \%$ \\
\hline $31-40$ yrs. & $8 \%$ \\
\hline $41-50$ yrs. & $22 \%$ \\
\hline $51-60$ yrs. & $32 \%$ \\
\hline $61-70$ yrs. & $26 \%$ \\
\hline \multicolumn{2}{|c|}{} \\
\hline
\end{tabular}

\begin{tabular}{|c|c|c|c|}
\hline & Right Eye & Left Eye & Both Eyes \\
\hline Number & 2 & 2 & 46 \\
\hline Percentage & $4 \%$ & $4 \%$ & $92 \%$ \\
\hline \multicolumn{4}{|c|}{ Table 2 } \\
\hline
\end{tabular}

\begin{tabular}{|c|c|c|c|}
\hline & Hypertension & $\begin{array}{c}\text { Ischaemic } \\
\text { Heart Disease }\end{array}$ & $\begin{array}{c}\text { Renal } \\
\text { Disease }\end{array}$ \\
\hline Number & 3 & 22 & 25 \\
\hline Percentage & $6 \%$ & $44 \%$ & $50 \%$ \\
\hline \multicolumn{3}{|c|}{ Table 3 } \\
\hline
\end{tabular}

\section{CONCLUSION}

Ischaemic maculopathy has no treatment as such, but can definitely be considered as a warning sign for future lifethreatening ischaemic cardiac events due to its strong association (85\%) and hence necessary steps of prevention should be taken with help of physicians.

\section{REFERENCES}

1. Nilam VKK. Regulation of blood glucose level in diabetes mellitus using palatable diet composition. Australasian Physics and Engineering Science in Medicine 2003;26(3):132-9.

2. Watkins PJ. Retinopathy. BMJ British Medical Journal 2003;327(7395):924-6.

3. Reznicek L, Kolb JP, Klein T, et al. Wide-field megahertz OCT imaging of patients with diabetic retinopathy. Journal of Diabetes Research 2015;2015:1-5.

4. Rechtman E, Harris A, Garzozi HJ, et al. Pharmacologic therapies for diabetic retinopathy and diabetic macular edema. Clinical Ophthalmology 2007;1(4):383-91.

5. Viswanath K, McGavin DDM. Diabetic retinopathy: clinical findings and management. Community Eye Health 2003;16(46):21-4.

6. Gardner TW, Gabbay RA. Diabetes and obesity-a challenge for every ophthalmologist. Arch Ophthalmol 2009;127(3):328-9.

7. Ellis D, Burgess PI, Kayange P. Management of diabetic retinopathy. Malawi Medical Journal 2013;25(4): 116-20.

8. Browning DJ, Altaweel MM, Bressler NM, et al. Diabetic macular edema: what is focal and what is diffuse? American Journal of Ophthalmology 2008;146(5):64955 e1-6.

9. Bresnick GH. Diabetic maculopathy: a critical review highlighting diffuse macular edema. Ophthalmology 1983;90(11):1301-17.

10. Klein R, Knudtson MD, Lee KE, et al. The Wisconsin epidemiologic study of diabetic retinopathy: XXII the twenty-five-year progression of retinopathy in persons with type 1 diabetes. Ophthalmology 2008;115(11): 1859-68.

11. Klein R, Klein BE, Moss SE, et al. The Wisconsin epidemiologic study of diabetic retinopathy. iv. diabetic macular edema. Ophthalmology 1984;91(12):1464-74. 